\title{
Associations of physical activity with neighborhood environments and transportation modes in older Japanese adults
}

\author{
Kenji Tsunoda ${ }^{a}$, Taishi Tsuji ${ }^{a}$, Naruki Kitano ${ }^{a}$, Yasuhiro Mitsuishi ${ }^{a}$, \\ Ji-Yeong Yoon ${ }^{b}$, Jieun Yoon ${ }^{\mathrm{a}}$, Tomohiro Okura ${ }^{\mathrm{b}}$
}

${ }^{\text {a }}$ Graduate School of Comprehensive Human Sciences, University of Tsukuba, Ibaraki, Japan 1-1-1 Tennodai, Tsukuba, Ibaraki 305-8574 Japan

${ }^{\mathrm{b}}$ Institute of Health and Sport Sciences, University of Tsukuba, Ibaraki, Japan 1-1-1 Tennodai, Tsukuba, Ibaraki 305-8574 Japan

\section{Corresponding author:}

Kenji Tsunoda

Graduate School of Comprehensive Human Sciences, University of Tsukuba

1-1-1 Tennodai, Tsukuba, Ibaraki 305-8574 Japan

TEL: +81-29-853-2639

FAX: +81-29-853-6507

E-mail: k.tsunoda.taiiku@gmail.com

\section{E-mail address of each author:}

Kenji Tsunoda: k.tsunoda.taiiku@gmail.com

Taishi Tsuji: s1130491@u.tsukuba.ac.jp

Naruki Kitano: n.kitano0911@gmail.com

Yasuhiro Mitsuishi: mitsuishiyasuhiro@yahoo.co.jp

Ji-Yeong Yoon: iniai77@yahoo.co.jp

Jieun Yoon: je7335@yahoo.co.jp

Tomohiro Okura: okura@taiiku.tsukuba.ac.jp 


\section{Abstract}

Objective: We investigated associations of walking and other leisure-time physical activity (LTPA) with environmental characteristics and transportation modes in older Japanese adults.

Methods: This cross-sectional study in 2010-2011 used data from 421 community-dwelling older adults aged 65-85 years living in Kasama City, rural Japan. We used the Physical Activity Scale for the Elderly to assess walking and other LTPAs, and the International Physical Activity Questionnaire Environment Module for neighborhood environments.

Results: After adjusting for confounders, we found that good traffic safety and aesthetics were positively associated with high levels of walking (ORs=1.64-2.12); whereas, good access to public transportation was negatively associated with walking (OR $=0.64,95 \%$ $\mathrm{CI}=0.42-0.98$ ). Good access to recreational facilities, presence of sidewalks, absence of hills, seeing people exercise, and aesthetically pleasing surroundings were positively associated with high levels of LTPA except walking $(\mathrm{ORs}=1.61-2.13)$. Individuals who rode bicycles more than once per week were more likely to engage in a LTPA except walking (1-3 days: $\mathrm{OR}=1.72,95 \% \mathrm{CI}=1.03-2.87 ; \geq 4$ days: $\mathrm{OR}=2.90,95 \% \mathrm{CI}=1.71-4.93)$.

Conclusion: This study adds information on correlates of physical activity among older Japanese adults; the positive association between LTPA except walking and the frequency of bicycle travel is an especially new and intriguing finding.

Keywords: Elderly, Walking, Exercise, Built environment, Public health 


\section{Introduction}

There is strong evidence that physical activity reduces the risk of all-cause mortality and many clinical conditions including disability, heart disease, stroke, and dementia (Blair et al., 2001; Nelson et al., 2007). Despite this array of important benefits, with advancing age physical activity typically decreases (Inoue et al., 2011a; Roberts and Dallal, 2005).

To promote physical activity, we need information about correlates of physical activity (Bauman et al., 2002). Growing evidence indicates that environmental characteristics such as access to recreational facilities, aesthetics, and traffic safety are associated with leisure-time physical activity (LTPA) in older adults (Inoue et al., 2011b; Santos et al., 2008; Van Cauwenberg et al., 2011; Wilcox et al., 2000). However, previous studies on this issue are limited because the majority of this type of research on older adults has been conducted in western countries. A recent systematic review (Van Cauwenberg et al., 2011) on environmental correlates of LTPA in older adults showed that over $90 \%$ of research papers were printed in North-America and Europe, with very few reports on Asian populations (Chen and $\mathrm{Fu}, 2008$; Inoue et al., 2011b). Studies on western populations are not always applicable to Asian people because of differences in urban forms, lifestyles and cultures. Furthermore, most previous studies assessed walking and/or total LTPA, which combined both walking and other LTPAs as the physical activity variables (Van Cauwenberg et al., 2011; Wendel-Vos et al., 2007), thus the environmental correlates for LTPA except walking are unclear. Walking can be performed almost anywhere with only comfortable shoes and clothes; whereas, many other LTPAs, such as table tennis, croquet, and golf, need a specific location and/or equipment. Separating these two types of information, walking and other LTPA, would help clarify effective interventions for increasing physical activity in older people. Finally, although some 
studies reported that good access to transportation was positively associated with LTPA (Besser and Dannenberg, 2005; Sallis et al., 2009), little is known about an association between transportation mode usage and LTPA. Our study aimed to investigate cross-sectional associations of walking and other LTPAs of older Japanese adults with environmental characteristics, frequency of travel by various transportation modes, and the main travel area.

\section{Methods}

Data collection

Older people living in Kasama City (population 79,409, area $240.3 \mathrm{~km}^{2}$ ), a rural region in Ibaraki Prefecture, Japan, participated in an open cohort study called "Kasama study" from 2009-2011 and were recruited as participants. In each of three years, men and women aged 65-85 years were randomly drawn from the Basic Resident Register and were added into the cohort. This study used cross-sectional data from the August 2010 and 2011 surveys. We drew 900 new people each from the 2010 and 2011 cohorts, and 213 individuals who were recruited in 2010 as a follow-up from the 2009 cohort study. Attributes of Kasama City (Ministry of Land, Infrastructure, Transport and Tourism, 2011; Government of Kasama City, 2011) appear in Table 1.

There were two steps for data collection. We first mailed invitation letters to the 2,013 older adults as described above, and received positive replies from 521 individuals. Second, we mailed a questionnaire to these 521 people who then filled it out and hand delivered it to the Health Center in Kasama City. All participants gave written informed consent when they passed the questionnaire to research staff. We collected 447 questionnaires. However, we 
rejected 13 incomplete questionnaires and another 13 individuals due to inability or difficulty ambulating leaving 421 participants (response rate 20.9\%) eligible for data analysis. This study was approved by the Ethical Committee of University of Tsukuba.

\section{Measurement variables}

Demographic variables included age, gender, educational level, work status (paid or volunteer), and clinical histories: heart disease, stroke, low back disease, knee and hip diseases (Table 2).

\section{Physical activity}

To gather LTPA information, we used the Japanese version of the Physical Activity Scale for the Elderly (PASE) (Hagiwara et al., 2008; Washburn et al., 1993). In this scale, LTPA consists of five activities: walking (for recreation and for transportation); light-, moderate-, and vigorous-intensity recreational activities; and muscle strength training. Each activity is measured by frequency (days during the previous 7 days) and time spent per day. Since this study focused on walking and other recreational activities, we excluded the muscle strength training. Although the International Physical Activity Questionnaire (IPAQ) in older Japanese adults has since been validated and confirmed (Tomioka et al., 2011), when we started the present investigation, the PASE was the best globally-recognized questionnaire available that was deemed reliable and valid for older Japanese adults.

A light-intensity activity in the PASE includes activities such as table tennis, croquet, and tai-chi. A moderate-intensity activity includes doubles tennis, ballroom dancing, and softball. 
The levels of these activities approximately corresponded to 3.0-5.9 METs (Ainsworth et al., 2000). Therefore, the total time spent on light- and moderate-intensity activity in the PASE was coded as moderate-intensity activity as defined by World Health Organization (WHO, 2010).

For walking, two dichotomous outcome variables were set using examples from a previous study (Gómez et al., 2010): (1) walking at least 60 minutes per week and (2) walking at least 150 minutes per week. LTPA except walking was also defined with two dichotomous variables similar to a previous report (Eyler, 2003): (1) sufficiently active, i.e. meeting the physical activity recommendation (WHO, 2010), which is engaging in at least 150 minutes per week of moderate-intensity activity or at least 75 minutes per week of vigorous-intensity activity, and (2) insufficiently active, i.e. engaging in either moderate or vigorous-intensity activity, but not enough to meet the recommendation.

\section{Environmental characteristics}

We used the Japanese version of the International Physical Activity Questionnaire Environment Module (IPAQ-E) (Inoue et al., 2009; IPS, 2002) to assess perceived neighborhood environments. In this study, 7 core items (residential density; access to shopping, public transportation, and recreational facilities; presence of sidewalks and bike lanes; and crime safety) and 4 recommended items (aesthetics; seeing people exercise; traffic safety; and number of household motor vehicles) were used. Since a recent study (Gómez et al. 2010) revealed that steep slopes were negatively associated with physical activity in older adults, we added one original question concerning the presence of hills: "There are many hills in my neighborhood which makes it difficult or unpleasant to walk or ride a bicycle. 
Would you say that you...". We framed this question in the style of the IPAQ-E questions (Inoue et al., 2009; IPS, 2002).

The question on residential density asks about the location of various types of neighborhood residences, with 5 response options from detached single family houses to apartments or condominiums 13 stories or higher. The question about household motor vehicles asks how many cars or motor bikes are in the household. The other 10 items are rated on a four-point Likert scale with "strongly disagree"; "somewhat disagree", "somewhat agree", and "strongly agree" as options.

Before the data analysis, residential density was divided into two categories: "detached single-family residences" indicating a low residential density, and other types of living arrangements, indicating a high residential density. The number of household motor vehicles was categorized as "none" and "one or more". Based on previous literature (Inoue et al., 2009; 2011b), we coded the other questions into binary variables: strongly agree and somewhat agree were coded as agree; and somewhat disagree and strongly disagree were coded as disagree.

\section{Transportation modes}

We used three variables to assess transportation mode usage: (1) frequency (days per week) of travel by bicycle; (2) frequency of travel by motor vehicle, either household vehicle, bus, train or taxi; and (3) the main travel area. We categorized the frequency of traveling by bicycle or motor vehicle as "less than once per week", "1-3 days per week", and "4 or more days per week". For determining the main travel area, participants were asked the question "Where do you mainly travel in a typical week?" Answers were set out as follows: "It is 
possible to travel by walking"; "It is possible to travel by bicycle"; and "It is possible to travel by motor vehicle". The three responses, respectively, defined the destination as a "walking area", "bicycle area", or "motor vehicle area". When analyzing the frequency of traveling by bicycle and the main travel area, we excluded 6 participants because they were riding their bicycles for the purpose of exercise.

\section{Statistical analysis}

We performed a logistic regression analysis to examine the association of walking and other LTPAs (dependent variables) with neighborhood environment and transportation modes (independent variables). We adjusted the odds ratios (ORs) and 95\% confidence intervals (95\% CIs) for age, gender, educational level, work status, and clinical histories. These factors are associated with physical activity (Burton and Turrell, 2000; Kaplan et al., 2001). In addition to the odds ratios, we also calculated $P$ for trend in transportation mode variables. We used SPSS 17.0 for statistical analysis with the level of significance set at $P<0.05$.

\section{Results}

Description of the sample

The mean age was 73.3 years, $19.7 \%$ walked $60-149$ minutes per week, and $52.7 \%$ walked more than 150 minutes per week (Table 2). For LTPA except walking, 10.7\% were insufficiently active, and $28.7 \%$ met the recommendations. 
Associations between environmental characteristics and walking

As shown in Table 3, older adults were more likely to walk at least 60 minutes per week when they perceived there was good traffic safety $(\mathrm{OR}=1.64,95 \% \mathrm{CI}=1.03-2.60)$ and pleasant aesthetics $(\mathrm{OR}=2.12,95 \% \mathrm{CI}=1.34-3.36)$. There was also a positive association between pleasant aesthetics $(\mathrm{OR}=2.00,95 \% \mathrm{CI}=1.33-3.02)$ and walking at least 150 minutes per week. On the other hand, good access to public transportation $(\mathrm{OR}=0.64,95 \%$ $\mathrm{CI}=0.42-0.98$ ) was negatively associated with walking at least 150 minutes per week.

Associations between transportation modes and walking

Participants who went out by motor vehicle more than once per week (1-3 days: $\mathrm{OR}=0.37,95 \% \mathrm{CI}=0.18-0.77$ ) were less likely to walk at least 150 minutes per week (trend $P$ $<0.05)$ (Table 4). Compared with participants in a walking area, those in motor vehicle areas $(\mathrm{OR}=0.35,95 \% \mathrm{CI}=0.19-0.64)$ and bicycle areas $(\mathrm{OR}=0.42,95 \% \mathrm{CI}=0.21-0.85)$ were less likely to walk at least 150 minutes per week (trend $P<0.05$ ). Furthermore, there was a negative association between a motor vehicle area $(\mathrm{OR}=0.44,95 \% \mathrm{CI}=0.21-0.90)$ and engaging in at least 60 minutes of walking per week.

Associations between environmental characteristics and LTPA except walking

Participants who reported good access to recreational facilities (OR=1.80, 95\% $\mathrm{CI}=1.19-2.73)$, the presence of sidewalks $(\mathrm{OR}=1.61,95 \% \mathrm{CI}=1.03-2.53)$, the absence of hills $(\mathrm{OR}=1.92,95 \% \mathrm{CI}=1.01-3.64)$, seeing people exercise $(\mathrm{OR}=1.87,95 \% \mathrm{CI}=1.07-3.30)$, or 
pleasant aesthetics $(\mathrm{OR}=1.66,95 \% \mathrm{CI}=1.10-2.52)$ were more likely to engage in some sort of LTPA except walking (Table 5). Good access to recreational facilities (OR=1.67, 95\% $\mathrm{CI}=1.07-2.62)$, the presence of sidewalks $(\mathrm{OR}=1.76,95 \% \mathrm{CI}=1.07-2.89)$, and pleasant aesthetics $(\mathrm{OR}=2.13,95 \% \mathrm{CI}=1.35-3.35)$ were significant factors for participants who were sufficiently active.

Associations between transportation modes and LTPA except walking

As Table 6 indicates, participants were more likely to engage in some sort of LTPA except walking when they rode a bicycle more than once per week (1-3 days: $\mathrm{OR}=1.72$, 95\% $\mathrm{CI}=1.03-2.87 ; \geq 4$ days: $\mathrm{OR}=2.90,95 \% \mathrm{CI}=1.71-4.93)$ (trend $P<0.05$ ). Similarly, participants were more likely to be sufficiently active when they rode a bicycle 1-3 days per week $(\mathrm{OR}=1.71,95 \% \mathrm{CI}=1.00-2.92)$. Bicycle $(\mathrm{OR}=3.42,95 \% \mathrm{CI}=1.66-7.04)$ and motor vehicle areas $(\mathrm{OR}=2.02,95 \% \mathrm{CI}=1.08-3.79)$ were positively associated with engagement in any physical activity except walking (trend $P<0.05$ ).

\section{Discussion}

This study found that perceived environmental characteristics and transportation modes are associated with high levels of walking and other LTPAs in older adults living in Kasama City. Over $60 \%$ of the area in Kasama City is forest and farm, and there is a low population density; it ranks 30th of the 44 cities in Ibaraki Prefecture in population density. Kasama City is typical of a rural region in Japan and our results would be especially applicable for such areas. 
Similar to our current findings, Gómez et al. (2010) found a positive link between good traffic safety and walking; whereas, another recent study in older Japanese adults (Inoue et al., 2011b) did not find this positive association. The divergence in results may be explained by different traffic situations and age groups studied. While our study and the Gómez et al. (2010) study included subjects over 75 years of age, Inoue et al. (2011b) looked at subjects 65-74 years old. Future research should examine the different effect of traffic safety on these two age groups.

An area with good access to public transportation is known as a walkable environment (Besser and Dannenberg, 2005; Sallis et al., 2009); however, we found a negative association between good access to public transportation and performing 150 minutes per week of walking. We believe this is the first study to find this negative association (Van Cauwenberg et al., 2011; Wendel-Vos et al., 2007), but it is not surprising to see a decrease in walking when public transportation is very near an individual's home and/or destination. The present study suggests that good access to public transportation might be negatively linked with high levels of walking depending on individuals' backgrounds.

Pleasant aesthetics were positively associated with the four physical activity variables, which is similar to other studies conducted in the United States (Michael et al., 2006), Brazil (Corseuil et al., 2011), and Japan (Inoue et al., 2011b). Pleasant aesthetics appears to be an important environmental factor for promoting physical activity in older adults.

We found a positive link between access to recreational facilities and LTPA except walking, but not with walking. Walking does not need a special venue to be performed, whereas, other LTPAs often require a specific location, therefore, good access to recreational facilities was only associated with LTPA except walking. In general, environmental characteristics were more often positively associated with LTPA except walking than they 
were associated with walking. Environmental characteristics would be more important for engaging in LTPA except walking than for exercising by walking alone.

The presence of sidewalks and the absence of hills were positive correlates of LTPA except walking. Santos et al. (2008) reported a strong association between the presence of sidewalks and access to destinations including recreational facilities, which we also observed (data not shown). The presence of sidewalks makes access to recreational facilities easier. The positive association between the absence of hills and LTPA except walking might be because our participants who traveled more by bicycle were more likely to engage in LTPA except walking. Perhaps the absence of hills indirectly increased LTPA by making it easier to ride a bicycle. Further detailed analyses such as structural equation models, are required to reveal these indirect associations.

We also explored whether the frequency of travel by various transportation modes and the main travel area are linked with walking and other LTPAs. Our results illustrated that daily travel by motor vehicle decreases walking time. On the other hand, the frequency of bicycle travel and the bicycle area correlated positively with LTPA except walking; these older Japanese adults may be riding a bicycle for access to recreational facilities. Recreational facilities set within the bicycle area of individuals' homes might help maintain or increase physical activity in older adults.

There were some limitations in our study. First, because this was a cross-sectional study, we cannot prove a causal association. Secondly, we combined the use of public transportation and household motor vehicles into our "frequency of travel by motor vehicle" variable. If we could divide this variable into two separate categories, we may have different results; this should be investigated in the future. Thirdly, our response rate was low. A previous Japanese study (Inoue et al., 2011b) provided an incentive for participation and reported a high 
collection rate, but we did not offer such an incentive. It is also possible that older adults living in Kasama City are wary of receiving mail from an unknown source and/or their motivation for this type of investigation may be low. Finally, since we assessed all research items through a self-administered questionnaire, results may be affected by reporting bias.

\section{Conclusion}

Three environmental characteristics correlated significantly with walking and five environmental characteristics correlated significantly with other LTPAs among older adults. Additionally, older adults who did not use a motor vehicle daily or rode a bicycle were more likely to engage in either high levels of walking or LTPA except walking, respectively. This information could be used to help promote physical activity among older Japanese adults.

\section{Conflict of interest statement}

The authors declare that there are no conflicts of interest.

\section{Acknowledgments}

This study was supported by the Ministry of Education, Culture, Sports, Science and Technology of Japan, Grant-in-Aid for Young Scientists (B), 22700690, 2010-2011.

\section{References}

Ainsworth BE, Haskell WL, Whitt MC, Irwin ML, Swartz AM, Strath SJ, O'Brien WL, Bassett DR, Schmitz KH, et al., 2000. Compendium of physical activities: an update of activity codes and MET intensities. Med Sci Sports Exerc 32: S498-S504. 
Bauman AE, Sallis JF, Dzewaltowski DA, Owen N, 2002. Toward a better understanding of the influences on physical activity: the role of determinants, correlates, causal variables, mediators, moderators, and confounders. Am J Prev Med 23: 5-14.

Besser LM and Dannenberg AL, 2005. Walking to public transit: steps to help meet physical activity recommendations. Am J Prev Med 29: 273-280.

Blair SN, Cheng Y, Holder JS, 2001. Is physical activity or physical fitness more important in defining health benefits?. Med Sci Sports Exerc 33: S379-S399.

Burton NW and Turrell G, 2000. Occupation, hours worked, and leisure-time physical activity. Prev Med 31: 673-681.

Chen SY and Fu YC, 2008. Leisure Participation and Enjoyment Among the Elderly: Individual Characteristics and Sociability. Educ Gerontol 34: 871-889.

Corseuil MW, Schneider IJ, Silva DA, Costa FF, Silva KS, Borges LJ, d'Orsi E, 2011. Perception of environmental obstacles to commuting physical activity in Brazilian elderly. Prev Med 53: 289-292.

Eyler AA, 2003. Personal, social, and environmental correlates of physical activity in rural Midwestern white women. Am J Prev Med 25: 86-92.

Gómez LF, Parra DC, Buchner D, Brownson RC, Sarmiento OL, Pinzón JD, Ardila M, Moreno J, Serrato M, et al., 2010. Built environment attributes and walking patterns among the elderly population in Bogotá. Am J Prev Med 38: 592-599.

Government of Kasama City, 2011. Statistical information of Kasama City. available at: http://www.city.kasama.lg.jp/cms/data/doc/1315196327_doc_14_0.pdf, accessed April, 2012.

Hagiwara A, Ito N, Sawai K, Kazuma K, 2008. Validity and reliability of the Physical Activity Scale for the Elderly (PASE) in Japanese elderly people. Geriatr Gerontol Int 8: 143-151.

Inoue S, Murase N, Shimomitsu T, Ohya Y, Odagiri Y, Takamiya T, Ishii K, Katsumura T, Sallis JF, 
2009. Association of physical activity and neighborhood environment among Japanese Adults. Prev Med 48: 321-325.

Inoue S, Ohya Y, Tudor-Locke C, Tanaka S, Yoshiike N, Shimomitsu T, 2011a. Time Trends for Step-Determined Physical Activity among Japanese Adults. Med Sci Sports Exerc 43: 1913-1919.

Inoue S, Ohya Y, Odagiri Y, Takamiya T, Kamada M, Okada S, Oka K, Kitabatake Y, Nakaya T, et al., 2011b. Perceived Neighborhood Environment and Walking for Specific Purposes Among Elderly Japanese. J Epidemiol 21: 481-490.

IPS, 2002. International Physical Activity Prevalence Study Environmental Survey Module. available at: http://www.drjamessallis.sdsu.edu/IPAQIPS.pdf, accessed April, 2012.

Kaplan MS, Newsom JT, McFarland BH, Lu L, 2001. Demographic and psychosocial correlates of physical activity in late life. Am J Prev Med 21: 306-312.

Michael Y, Beard T, Choi D, Farquhar S, Carlson N, 2006. Measuring the influence of built neighborhood environments on walking in older adults. J Aging Phys Act 14: 302-312.

Ministry of Land, Infrastructure, Transport and Tourism, 2011. National Land Numerical Information download service. available at: http://nlftp.mlit.go.jp/ksj-e/jpgis/jpgis_datalist.html, accessed April, 2012.

Nelson ME, Rejeski WJ, Blair SN, Duncan PW, Judge JO, King AC, Macera CA, Castaneda-Sceppa C, 2007. Physical activity and public health in older adults: recommendation from the American College of Sports Medicine and the American Heart Association. Med Sci Sports Exerc 39: 1435-1445.

Roberts SB and Dallal GE, 2005. Energy requirements and aging. Public Health Nutr 8: 1028-1036.

Sallis JF, Bowles HR, Bauman A, Ainsworth BE, Bull FC, Craig CL, Sjöström M, De Bourdeaudhuij I, Lefevre J, et al., 2009. Neighborhood environments and physical activity among adults in 
11 countries. Am J Prev Med 36: 484-490.

Santos R, Silva P, Santos P, Ribeiro JC, Mota J, 2008. Physical activity and perceived environmental attributes in a sample of Portuguese adults: results from the Azorean Physical Activity and Health study. Prev Med 47: 83-88.

Tomioka K, Iwamoto J, Saeki K, Okamoto N, 2011. Reliability and validity of the International Physical Activity Questionnaire (IPAQ) in elderly adults: the Fujiwara-kyo Study. J Epidemiol 21: 459-465.

Van Cauwenberg J, De Bourdeaudhuij I, De Meester F, Van Dyck D, Salmon J, Clarys P, Deforche B, 2011. Relationship between the physical environment and physical activity in older adults: a systematic review. Health Place 17: 458-469.

Washburn RA, Smith KW, Jette AM, Janney CA, 1993. The Physical Activity Scale for the Elderly (PASE): development and evaluation. J Clin Epidemiol 46: 153-162.

Wendel-Vos W, Droomers M, Kremers S, Brug J, van Lenthe F, 2007. Potential environmental determinants of physical activity in adults: a systematic review. Obes Rev 8: 425-440.

Wilcox S, Castro C, King AC, Housemann R, Brownson RC, 2000. Determinants of leisure time physical activity in rural compared with urban older and ethnically diverse women in the United States. J Epidemiol Community Health 54: 667-672.

World Health Organization, 2010. Global Recommendation on Physical Activity for Health. available at: http://whqlibdoc.who.int/publications/2010/9789241599979_eng.pdf, accessed April, 2012. 
Table 1. Attributes of Kasama City (Ibaraki, Japan, 2011).

\begin{tabular}{lr}
\hline Population $(\mathrm{n})$ & 79,409 \\
Population aging rate $(\%)$ & 24.0 \\
Population density $\left(\mathrm{n} / \mathrm{km}^{2}\right)$ & 330.5 \\
Total area $\left(\mathrm{km}^{2}\right)$ & 240.3 \\
$\quad$ Building area $\left(\mathrm{km}^{2}\right)$ & 22.3 \\
Forest area $\left(\mathrm{km}^{2}\right)$ & 85.6 \\
Farmland area $\left(\mathrm{km}^{2}\right)$ & 63.4 \\
Other areas $\left(\mathrm{km}^{2}\right)$ & 69.0 \\
- Park area $(\mathrm{ha})$ & 70.5 \\
$\quad$ Park (n) & 22 \\
$\quad$ Park density $\left(\mathrm{n} / 10 \mathrm{~km}^{2}\right)$ & 0.92 \\
Inhabitable area $\left(\mathrm{km}^{2}\right)$ & 137.6 \\
Train stations $(\mathrm{n})$ & 6 \\
Bus stops $(\mathrm{n})$ & 97 \\
Public transportation (train stations & 0.43 \\
and bus stops) density $\left(\mathrm{n} / \mathrm{km}^{2}\right)$ & \\
\hline Al
\end{tabular}

All information referred by Ministry of Land, Infrastructure, Transport and Tourism (2011) and Government of Kasama City (2011). 
Table 2. Participant characteristics (Ibaraki, Japan, 2010-2011).

\begin{tabular}{|c|c|c|}
\hline & & $(\%)$ \\
\hline \multicolumn{3}{|l|}{ Age (years) } \\
\hline $65-74$ & 258 & (61.3) \\
\hline $75-85$ & 163 & (38.7) \\
\hline mean $\pm S D$ & 73.3 & \pm 5.3 \\
\hline \multicolumn{3}{|l|}{ Gender } \\
\hline Male & 200 & $(47.5)$ \\
\hline Female & 221 & (52.5) \\
\hline \multicolumn{3}{|l|}{ Education (years) } \\
\hline $6-9$ & 126 & (29.9) \\
\hline $10-12$ & 204 & (48.5) \\
\hline $13+$ & 91 & (21.6) \\
\hline \multicolumn{3}{|l|}{ Work status (h/week) } \\
\hline 0 & 278 & $(66.0)$ \\
\hline $1-19$ & 80 & (19.0) \\
\hline $20-39$ & 41 & $(9.7)$ \\
\hline $40+$ & 22 & (5.2) \\
\hline \multicolumn{3}{|c|}{ Clinical histories } \\
\hline Heart disease & 57 & (13.5) \\
\hline Stroke & 11 & (2.6) \\
\hline Low back disease & 86 & (20.4) \\
\hline Knee disease & 65 & $(15.4)$ \\
\hline Hip disease & 14 & (3.3) \\
\hline \multicolumn{3}{|c|}{ Physical activity } \\
\hline \multicolumn{3}{|c|}{ Walking (min/week) } \\
\hline $\begin{array}{l}150+ \\
60-149\end{array}$ & $\begin{array}{r}222 \\
83\end{array}$ & $\begin{array}{l}(52.7) \\
(19.7)\end{array}$ \\
\hline$<60$ & 116 & (27.6) \\
\hline \multicolumn{3}{|l|}{ LTPA except for walking } \\
\hline Sufficiently active ${ }^{\dagger}$ & 121 & (28.7) \\
\hline Insufficiently active & 45 & $(10.7)$ \\
\hline Inactive & 255 & $(60.6)$ \\
\hline
\end{tabular}

LTPA: leisure-time physical activity

${ }^{\dagger}$ Sufficiently active: meeting WHO recommendations (engaging in at least $150 \mathrm{~min} /$ week of moderate-intensity activity or at least $75 \mathrm{~min} /$ week of vigorous-intensity activity). Insufficiently active: engaging in any physical activity but not meeting recommendation. Inactive: not engaging in any physical activity. 
Table 3. Adjusted associations between high levels of walking and perceived environments in older adults (Ibaraki, Japan, 2010-2011).

\begin{tabular}{|c|c|c|c|c|c|c|}
\hline \multirow{3}{*}{ Residential density } & \multirow{2}{*}{\multicolumn{2}{|c|}{$\mathrm{n}(\%)$}} & \multicolumn{2}{|c|}{ Walking $\geq 60 \mathrm{~min} /$ week } & \multicolumn{2}{|c|}{ Walking $\geq 150 \mathrm{~min} /$ week } \\
\hline & & & \multirow{2}{*}{ Odds ratios } & \multirow[t]{2}{*}{$95 \% \mathrm{Cl}$} & \multirow[t]{2}{*}{ Odds ratios } & \multirow[t]{2}{*}{$95 \% \mathrm{Cl}$} \\
\hline & & & & & & \\
\hline High & 33 & (7.8) & 0.96 & $(0.43-2.16)$ & 0.82 & $(0.39-1.72)$ \\
\hline Low & 388 & (92.2) & 1.00 & & 1.00 & \\
\hline \multicolumn{7}{|l|}{ Access to shops } \\
\hline Good & 254 & $(60.5)$ & 1.02 & $(0.65-1.60)$ & 0.67 & $(0.45-1.02)$ \\
\hline Poor & 166 & (39.5) & 1.00 & & 1.00 & \\
\hline \multicolumn{7}{|c|}{ Access to public transportation } \\
\hline Good & 265 & $(63.1)$ & 0.78 & $(0.48-1.24)$ & 0.64 & $(0.42-0.98)$ \\
\hline Poor & 155 & $(36.9)$ & 1.00 & & 1.00 & \\
\hline \multicolumn{7}{|c|}{ Access to recreational facilities } \\
\hline Good & 226 & $(54.1)$ & 1.15 & $(0.74-1.81)$ & 1.20 & $(0.80-1.80)$ \\
\hline Poor & 192 & $(45.9)$ & 1.00 & & 1.00 & \\
\hline \multicolumn{7}{|c|}{ Presence of sidewalks } \\
\hline Yes & 287 & $(68.5)$ & 0.72 & $(0.44-1.18)$ & 0.73 & $(0.48-1.13)$ \\
\hline No & 132 & $(31.5)$ & 1.00 & & 1.00 & \\
\hline \multicolumn{7}{|c|}{ Presence of bike lanes } \\
\hline Yes & 160 & $(38.1)$ & 0.97 & $(0.62-1.53)$ & 0.95 & $(0.63-1.43)$ \\
\hline No & 260 & (61.9) & 1.00 & & 1.00 & \\
\hline \multicolumn{7}{|l|}{ Traffic safety } \\
\hline Safe & 250 & $(59.8)$ & 1.64 & $(1.03-2.60)$ & 1.46 & $(0.96-2.21)$ \\
\hline Not safe & 168 & $(40.2)$ & 1.00 & & 1.00 & \\
\hline \multicolumn{7}{|l|}{ Crime safety } \\
\hline Safe & 289 & $(69.5)$ & 0.69 & $(0.41-1.15)$ & 0.94 & $(0.60-1.48)$ \\
\hline Not safe & 127 & $(30.5)$ & 1.00 & & 1.00 & \\
\hline \multicolumn{7}{|l|}{ Presence of hills } \\
\hline No & 360 & $(85.7)$ & 1.44 & $(0.77-2.69)$ & 1.12 & $(0.63-2.02)$ \\
\hline Yes & 60 & $(14.3)$ & 1.00 & & 1.00 & \\
\hline \multicolumn{7}{|c|}{ Seeing people exercise } \\
\hline Yes & 346 & $(82.4)$ & 0.89 & $(0.49-1.60)$ & 1.04 & $(0.62-1.76)$ \\
\hline No & 74 & $(17.6)$ & 1.00 & & 1.00 & \\
\hline \multicolumn{7}{|l|}{ Aesthetics } \\
\hline Good & 205 & $(48.9)$ & 2.12 & $(1.34-3.36)$ & 2.00 & $(1.33-3.02)$ \\
\hline Poor & 214 & $(51.1)$ & 1.00 & & 1.00 & \\
\hline \multicolumn{7}{|c|}{ Household car or motor bike } \\
\hline One or more & 390 & $(93.1)$ & 1.63 & $(0.70-3.77)$ & 0.72 & $(0.33-1.61)$ \\
\hline None & 29 & (6.9) & 1.00 & & 1.00 & \\
\hline
\end{tabular}

Bold numbers indicate $P<0.05$.

Odds ratios and $95 \%$ confidence intervals were adjusted for age, gender, educational level, work status, and clinical histories: heart disease, stroke, low back disease, knee disease, and hip disease. 
Table 4. Adjusted associations beween high levels of walking and transportation modes in older adults (Ibaraki, Japan, 2010-2011).

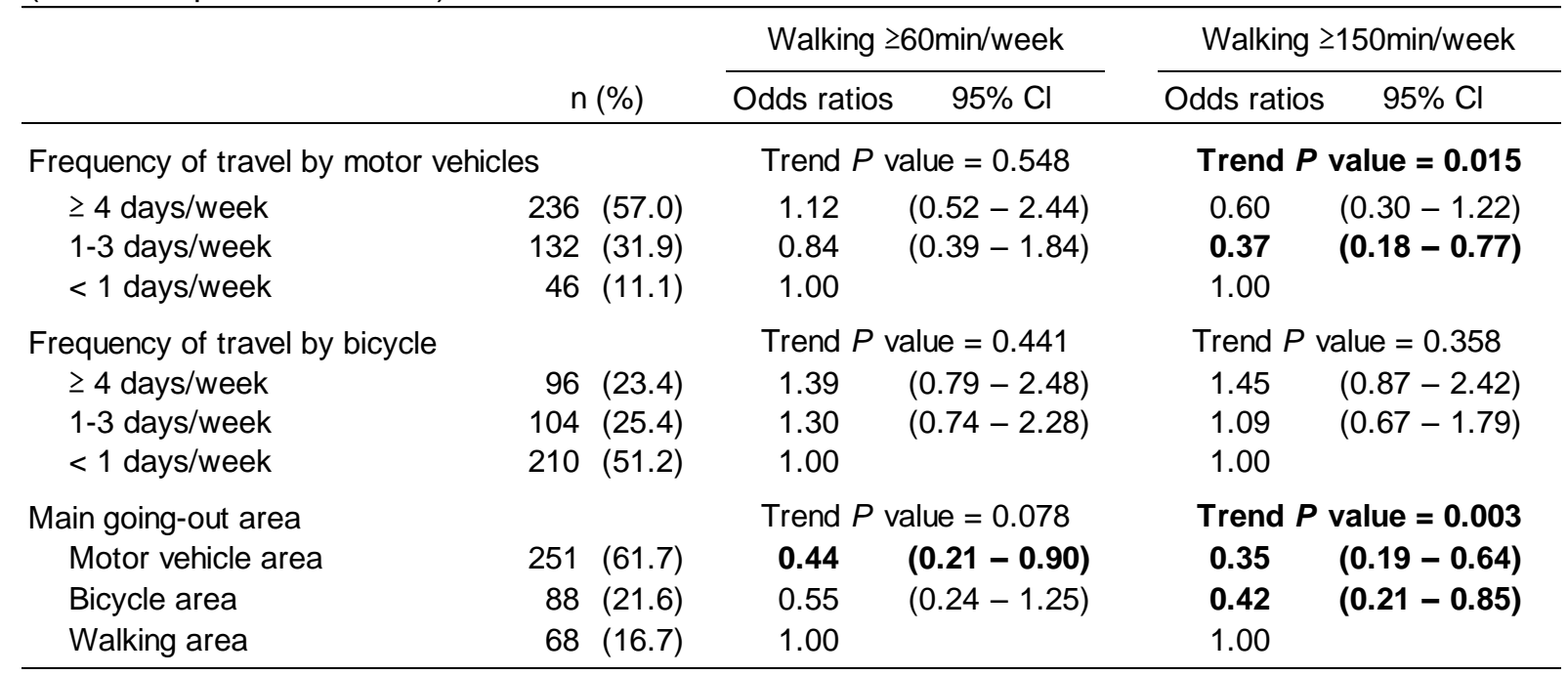

Bold numbers indicate $P<0.05$.

Odds ratios and $95 \%$ confidence intervals were adjusted for age, gender, educational level, work status, and clinical histories: heart disease, stroke, low back disease, knee disease, and hip disease. 
Table 5. Adjusted associations beween high levels of leisure-time physical activity except walking and perceived environments in older adults (Ibaraki, Japan, 2010-2011).

\begin{tabular}{|c|c|c|c|c|c|c|}
\hline & \multirow{2}{*}{\multicolumn{2}{|c|}{$n(\%)$}} & \multicolumn{2}{|c|}{$\begin{array}{c}\text { Sufficently active }+ \\
\text { insufficently active vs. inactive } \\
\text { (except walking) }\end{array}$} & \multicolumn{2}{|c|}{$\begin{array}{l}\text { Sufficently active vs. } \\
\text { insufficently active + inactive } \\
\text { (except walking) }\end{array}$} \\
\hline & & & Odds ratios & $95 \% \mathrm{Cl}$ & Odds ratios & $95 \% \mathrm{Cl}$ \\
\hline \multicolumn{7}{|c|}{ Residential density } \\
\hline High & 33 & $(7.8)$ & 1.09 & $(0.51-2.32)$ & 1.26 & $(0.56-2.81)$ \\
\hline Low & 388 & (92.2) & 1.00 & & 1.00 & \\
\hline \multicolumn{7}{|l|}{ Access to shops } \\
\hline Good & 254 & $(60.5)$ & 1.33 & $(0.88-2.02)$ & 1.14 & $(0.73-1.79)$ \\
\hline Poor & 166 & (39.5) & 1.00 & & 1.00 & \\
\hline \multicolumn{7}{|c|}{ Access to public transportation } \\
\hline Good & 265 & $(63.1)$ & 1.16 & $(0.76-1.77)$ & 1.19 & $(0.75-1.88)$ \\
\hline Poor & 155 & $(36.9)$ & 1.00 & & 1.00 & \\
\hline \multicolumn{7}{|c|}{ Access to recreational facilities } \\
\hline Good & 226 & $(54.1)$ & 1.80 & $(1.19-2.73)$ & 1.67 & $(1.07-2.62)$ \\
\hline Poor & 192 & (45.9) & 1.00 & & 1.00 & \\
\hline \multicolumn{7}{|c|}{ Presence of sidewalks } \\
\hline Yes & 287 & (68.5) & 1.61 & $(1.03-2.53)$ & 1.76 & $(1.07-2.89)$ \\
\hline No & 132 & $(31.5)$ & 1.00 & & 1.00 & \\
\hline \multicolumn{7}{|c|}{ Presence of bike lanes } \\
\hline Yes & 160 & $(38.1)$ & 1.15 & $(0.76-1.75)$ & 1.39 & $(0.88-2.17)$ \\
\hline No & 260 & (61.9) & 1.00 & & 1.00 & \\
\hline \multicolumn{7}{|l|}{ Traffic safety } \\
\hline Safe & 250 & $(59.8)$ & 0.93 & $(0.61-1.43)$ & 1.29 & $(0.81-2.05)$ \\
\hline Not safe & 168 & $(40.2)$ & 1.00 & & 1.00 & \\
\hline \multicolumn{7}{|l|}{ Crime safety } \\
\hline Safe & 289 & (69.5) & 1.09 & $(0.69-1.71)$ & 0.99 & $(0.61-1.62)$ \\
\hline Not safe & 127 & $(30.5)$ & 1.00 & & 1.00 & \\
\hline \multicolumn{7}{|l|}{ Presence of hills } \\
\hline No & 360 & (85.7) & 1.92 & $(1.01-3.64)$ & 1.56 & $(0.77-3.17)$ \\
\hline Yes & 60 & (14.3) & 1.00 & & 1.00 & \\
\hline \multicolumn{7}{|c|}{ Seeing people exercise } \\
\hline Yes & 346 & (82.4) & 1.87 & $(1.07-3.30)$ & 1.83 & $(0.98-3.43)$ \\
\hline No & 74 & $(17.6)$ & 1.00 & & 1.00 & \\
\hline \multicolumn{7}{|l|}{ Aesthetics } \\
\hline Good & 205 & (48.9) & 1.66 & $(1.10-2.52)$ & 2.13 & $(1.35-3.35)$ \\
\hline Poor & 214 & (51.1) & 1.00 & & 1.00 & \\
\hline \multicolumn{7}{|c|}{ Household car or motor bike } \\
\hline One or more & 390 & (93.1) & 1.50 & $(0.65-3.49)$ & 1.49 & $(0.57-3.87)$ \\
\hline None & 29 & (6.9) & 1.00 & & 1.00 & \\
\hline
\end{tabular}

Bold numbers indicate $P<0.05$.

Odds ratios and $95 \%$ confidence intervals were adjusted for age, gender, educational level, work status, and clinical histories: heart disease, stroke, low back disease, knee disease, and hip disease.

'Sufficiently active: meeting WHO recommendation of engaging in at least $150 \mathrm{~min} /$ week of moderate-intensity activity or at least $75 \mathrm{~min} /$ week of vigorous-intensity activity. Insufficiently active: engaging in any physical activity but not meeting the recommendation. Inactive: not engaging in any physical activity. 
Table 6. Adjusted associations between high levels of leisure-time physical activity except walking and transportation modes in older adults (Ibaraki, Japan, 2010-2011).

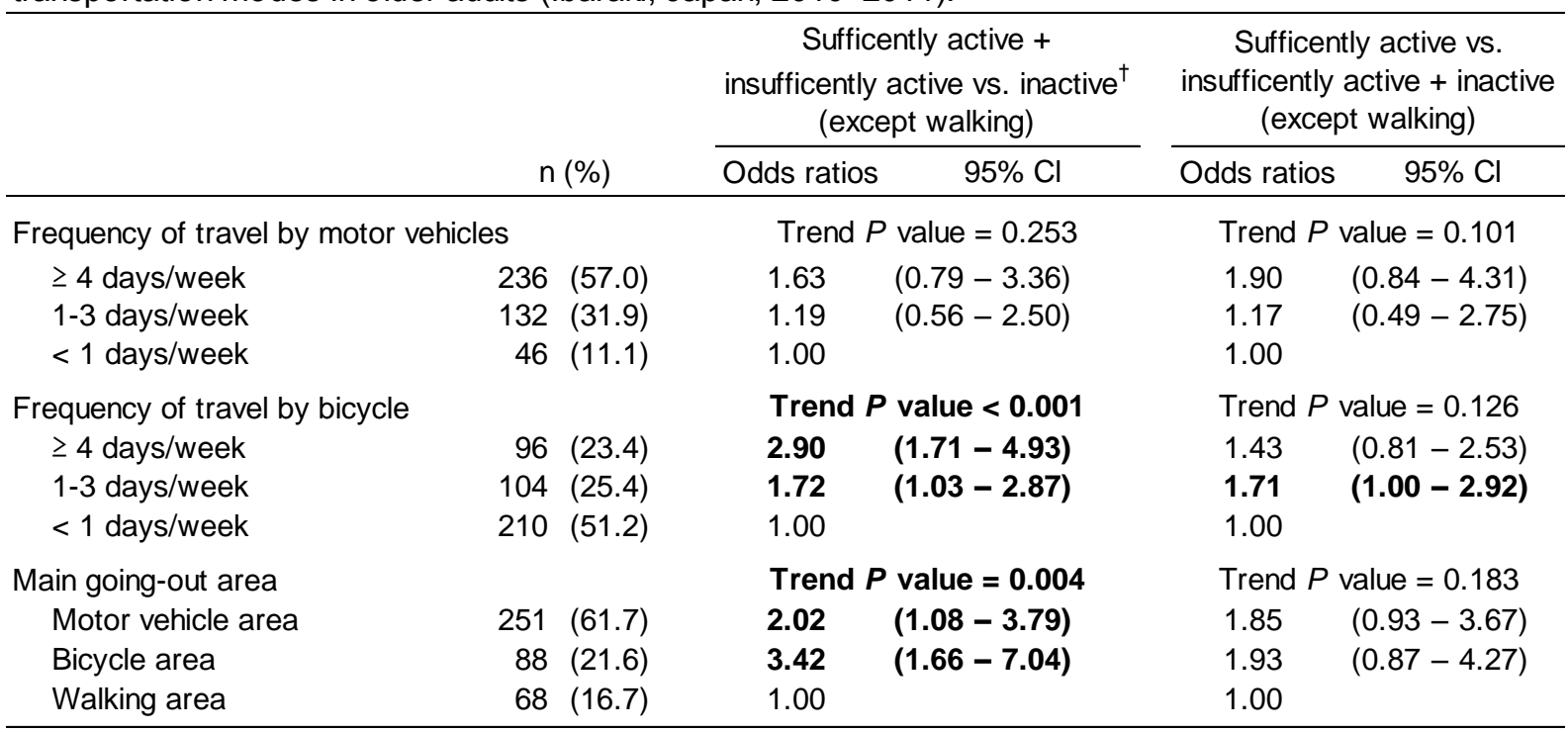

Bold numbers indicate $P<0.05$.

Odds ratios and $95 \%$ confidence intervals were adjusted for age, gender, educational level, work status, and clinical histories: heart disease, stroke, low back disease, knee disease, and hip disease.

${ }^{\dagger}$ Sufficiently active: meeting WHO recommendation of engaging in at least $150 \mathrm{~min} /$ week of moderate-intensity activity or at least $75 \mathrm{~min} /$ week of vigorous-intensity activity. Insufficiently active: engaging in any physical activity but not meeting the recommendation. Inactive: not engaging in any physical activity. 